\title{
Design of Low Profile Multiband USB Dongle Antenna
}

\author{
Hemin Ismael Azeez $^{1} \quad$ Shorsh Kareem Ahmed $^{2} \quad$ Mohamed Abdullah Husain $^{3}$ \\ ${ }^{1}$ Sulaimani Polytechnic University, Technical College of Engineering, Communication Engineering Department, Sulaimani, \\ Kurdistan Region, Iraq \\ hemin.azeez@spu.edu.iq \\ ${ }^{2}$ Sulaimani Polytechnic University, Darbandikhan Technical Institute, Electrical \\ Department, Darbandikhan, Sulaimani, Kurdistan Region, Iraq \\ shorsh.ahmed@spu.edu.iq \\ ${ }^{3}$ Sulaimani Polytechnic University, Technical College of Engineering, Communication Engineering Department, Sulaimani, \\ Kurdistan Region, Iraq \\ zheermo@yahoo.com
}

\begin{abstract}
A dual band F-shaped printed mono-pole antenna (USB dongle) with two meandered strips is proposed and tested. The two strips that resonating at $2.45 \mathrm{GHz}$ and 5.2 GHz have uniform and fixed width of $0.5 \mathrm{~mm}$. A thin layer of $0.8 \mathrm{~mm}$ thickness FR4 substrate (permittivity $=4.4$, loss tangent=0.0245) which is economically cheap is used for the unit fabrication. The two resonant modes will best support Bluetooth (BT) and WLAN (Wireless Local Area Network) having enough supportive bandwidth which is defined by $10 \mathrm{~dB}$ reflection coefficient. The proposed unit is low profile, compact and simple to fabricate. The whole unit that has an overall size of $(0.8 \mathrm{~mm} \times 10 \mathrm{~mm} \times 40 \mathrm{~mm})$ is efficient for having $97 \%$ and $94 \%$ total radiation efficiency at both operating frequencies respectively. Through applying different simulation scenarios to the unit such as varying the feeding location and changes in the strips length, it has been revealed that the antennas is sensitive and reactive. The proposed antenna has provided good performance and Omni-directional radiation pattern. Good matching between the simulated and measured reflection coefficient results for the antenna prototype has been achieved.
\end{abstract}

Keywords: Low profile, Impedance band width, Radiation efficiency, Reflection coefficient.

\section{Introduction}

Nowadays Universal Serial Bus (USB) dongle antennas are widely used in Small and portable wireless electronics. To be user friendly [1] and [2] argued that the USB antenna must keep its profile small and compact. Double sided dongle antenna design is one way of art in antenna design which is proposed in [3] but it's worth mentioning that the antenna is more complex to manufacture. In this manner, non-planar dongle antennas will also add complexity to manufacturing process is proposed [4]. Simple and small antenna structures to be a good choice for portable dongle antennas are the drawback of some researchers carried out in both [5] and [6] regarding antenna design. Dongle antennas are desired to be small in size, compact, planar and multi band. To add more, the antenna performance and Omni-directional radiation patterns are from the key points that need to be taken into serious consideration. In this paper, a small size meandered monopole antenna proposed for WLAN applications. The following sections will describe the antenna structure and operation bands then discuses simulation and measured results for the antenna parameters.

\section{Antenna Design and Operation Bands}

The proposed antenna unit geometry for Universal Serial Bus (USB) dongle applications is presented in figure 1. The planar unit is printed on FR4 substrate with $0.8 \mathrm{~mm}$ thickness which is very cheap material having the material specifications of (4.4) permittivity and (0.0245) loss tangent. The low profile dongle antenna has overall dimensions of $40 \mathrm{~mm} \times 10 \mathrm{~mm}$ (W x L) which is mainly composed of two parts. The larger section is the ground plane with $10 \mathrm{~mm} \times 30 \mathrm{~mm}$ (W x L1) which is lossy copper conductor with almost $0.035 \mathrm{~mm}$ thickness. The upper section with $10 \mathrm{~mm} \times 9.5 \mathrm{~mm}(\mathrm{~W} \times \mathrm{L} 2)$ is the dual band mono-pole antenna, with two meandered strips each of fixed $0.5 \mathrm{~mm}$ conductor width.

The upper part is modelled in a way that each strip mainly is responsible for a band of frequency, in addition there is interaction between the two paths on each band performance. The longer path on one hand is mainly responsible in controlling the $2.45 \mathrm{GHz}$ band frequency and the shorter path on the other hand is controlling the higher band $5.2 \mathrm{GHz}$ frequency. The details of the proposed unit dimensions is summarized in table 1.
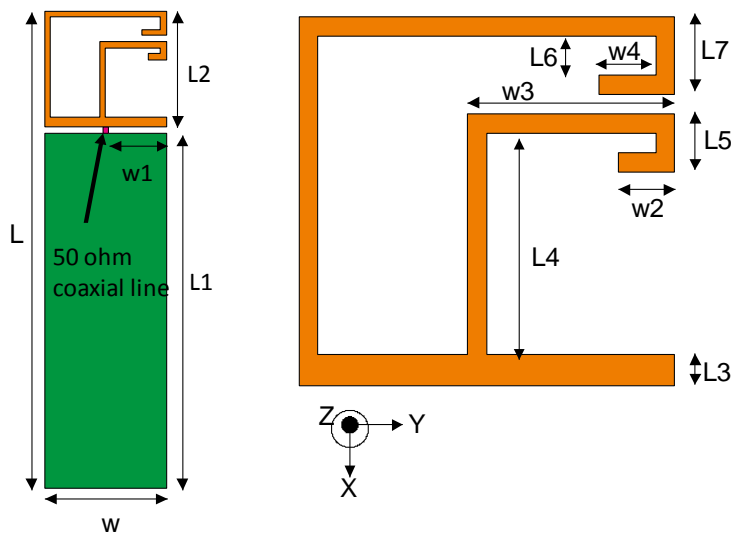

Figure 1: Geometry of the proposed USB dongle antenna

The mono-pole antenna is fed with RF at the centre with a $50 \mathrm{ohm}$ coaxial line. The proposed unit in this paper is 
modelled using HFSS High Frequency Structure Simulator. The antenna provides good matching between the simulated and the measured s-parameter results. As it is shown in figure 2 which depicts simulated and measured return loss for the unit, the $10 \mathrm{~dB}$ return loss bandwidth supports IEEE $802.11 \mathrm{a} / \mathrm{b} / \mathrm{g}$ standards operating at (2.4-2.484 GHz) and (5.150-5.350GHz).

Moreover, from measured return loss results, it can be noticed that the antenna has a wide impedance band width at the higher band frequency by which other applications such as HIPERLAN ( High Performance Radio Local Area Networks) and upper frequency band of ISM (Industrial, Scientific and Medical ) are also supported.

Table 1: Details of the proposed antenna dimensions

\begin{tabular}{|c|c|c|c|c|c|c|c|c|}
\hline $\begin{array}{c}\text { Paramete } \\
\mathbf{r}\end{array}$ & $\mathbf{L}$ & $\mathbf{L 1}$ & $\mathbf{L 2}$ & $\mathbf{L 3}$ & $\mathbf{L 4}$ & $\mathbf{L 5}$ & $\mathbf{L 6}$ & $\begin{array}{c}\text { L } \\
\mathbf{7}\end{array}$ \\
\hline Unit(mm) & 4 & 30 & 9.5 & 0.8 & 5.7 & 1.5 & 1 & 2 \\
\hline $\begin{array}{c}\text { Paramete } \\
\mathbf{r}\end{array}$ & $\mathrm{W}$ & $\mathrm{W} 1$ & $\mathrm{~W}$ & $\mathrm{~W}$ & $\mathrm{~W}$ & $\begin{array}{c}\text { Copper } \\
\text { thicknes } \\
\text { s }\end{array}$ & \\
\hline Unit(mm) & 1 & $\begin{array}{c}4.7 \\
5\end{array}$ & 1.5 & 5.5 & 1.5 & 0.035 & \\
\hline
\end{tabular}

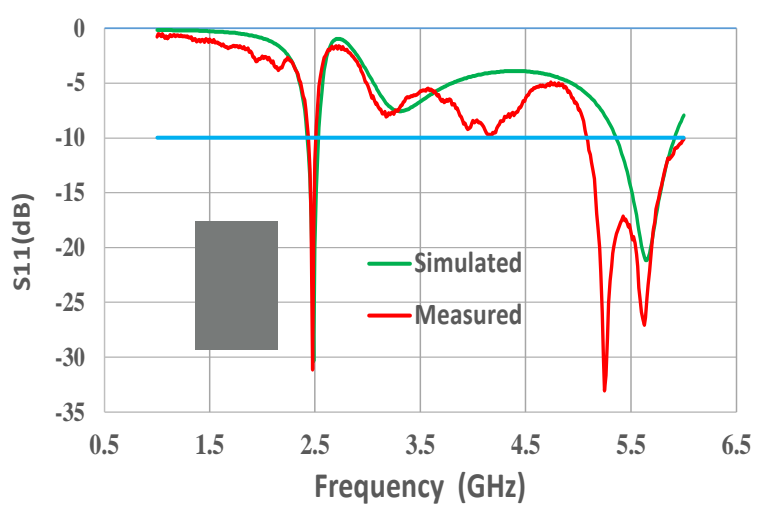

Figure 2: Simulated and measured return loss of the unit

\section{Results and Discussions}

In antenna design, one of the key points is finding the exact position that the antenna can be excited with the operating radio frequency. This means proper impedance matching can be achieved at the specified feeding point that will help engineers to keep the design simple and not insert extra impedance matching networks to increase the antenna performance. Figure 3 presents how changing the feeding point will affect the return loss (-S11).

The fabricated unit which is fed at the centre can also be fed at point 1 which is exactly $(2.5 \mathrm{~mm})$ away from the right edge of the f-shaped monopole antenna. As it can be observed from simulated return loss, better impedance matching can also be achieved at both $(2.45 \mathrm{GHz}$ and 5.2 $\mathrm{GHz}$ ) bands, with slight shift in lower band resonance frequency that can also be mitigated with slightly decreasing the length of the longer strip. It is worth to mention that, in consistence to impedance matching, the antenna has a wider impedance band width which is taken at $-10 \mathrm{~dB}$ and implies only $10 \%$ of the excited power is reflected back and VSWR $<2$. However, moving the feed point to point 2 on the left side of the antenna, will enhance impedance mismatching of the antenna.

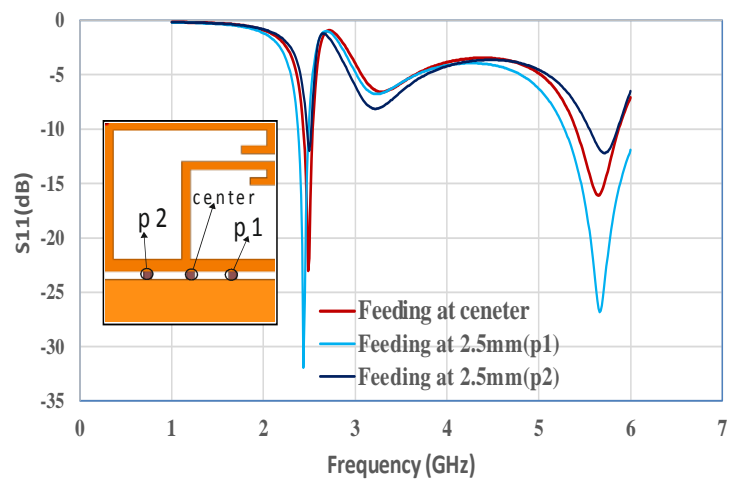

Figure 3: Testing for different feeding points of the unit

Figure 4 depicts that the scenario of controlling the resonance modes by slightly increasing and decreasing the length of each of the strips individually. From the Simulated results for return loss, it can be seen that the lower operating band $2.45 \mathrm{GHz}$ is mainly controlled by the longer strip (strip 1), increasing the length of strip 1 slightly by $2 \mathrm{~mm}$ from the end, significant shift in the lower band resonance frequency will occur. In addition, any changes in the length of strip 2 will result in frequency shifts in the upper band frequency $5.2 \mathrm{GHz}$.

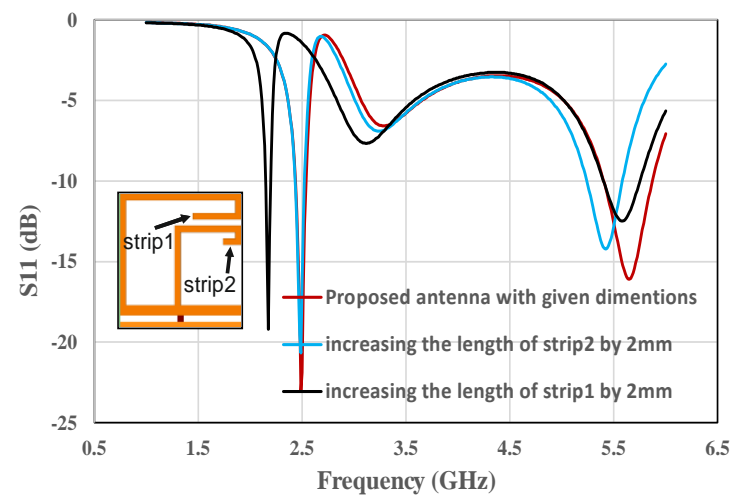

Figure 4: Testing for different strip lengths

More Simulation tests about far field radiation pattern, antenna gain and radiation efficiency are carried out in the following sections. In figure 5(a,b) 3-D radiation pattern for the proposed antenna at both $2.45 \mathrm{GHz}$ and $\% .2 \mathrm{GHz}$ are presented. The radiation pattern in all the Cartesian planes (X-Y, X-Z and Y-Z) are observed. The Y-Z plane view for radiation pattern reveals that the antenna is roughly providing Omni-directional radiation pattern for both the frequency band $2.45 \mathrm{GHz}$ and $5.2 \mathrm{GHz}$. The Radiation pattern is smooth for the lower band and minor lobe radiation can be seen along the $\mathrm{X}-\mathrm{Z}$ plane for upper band frequency.

Figure $6 a$ and $6 b$ show gain and radiation efficiency simulated results of the unit. As it can be seen from the results, the antenna has almost a steady state for gain and radiation efficiency at both lower and upper bands. For lower band frequency $2.45 \mathrm{GHz}$, antenna gain is between 1.64 and $1.70 \mathrm{dBi}$ with radiation efficiency $97-98.8 \%$. Figure $6 \mathrm{~b}$ presents that the antenna is more efficient at the upper band $5.2 \mathrm{GHz}$, the antenna gain is gradually 
increases from 5.16 to $5.8 \mathrm{dBi}$ with radiation efficiency of above $94 \%-99 \%$.

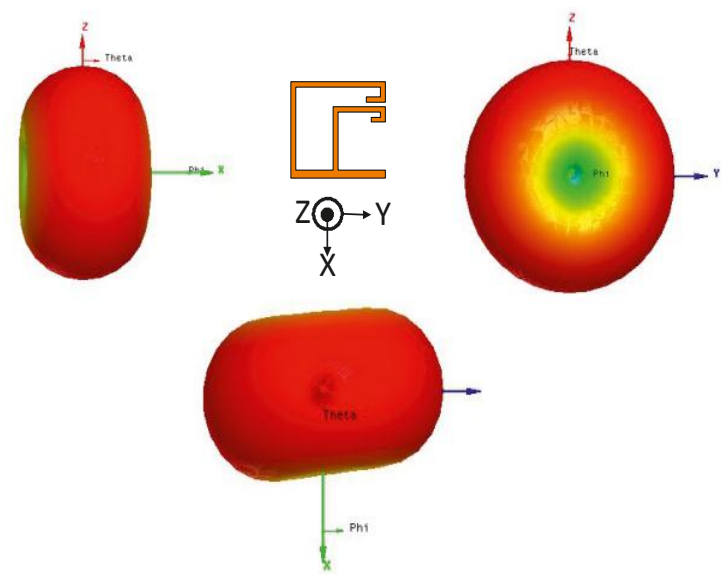

Figure 5a: 3-D simulated radiation patterns in $\mathrm{Y}-\mathrm{Z}, \mathrm{X}-\mathrm{Z}$, and $\mathrm{X}-\mathrm{Y}$ plane at $2.45 \mathrm{GHz}$

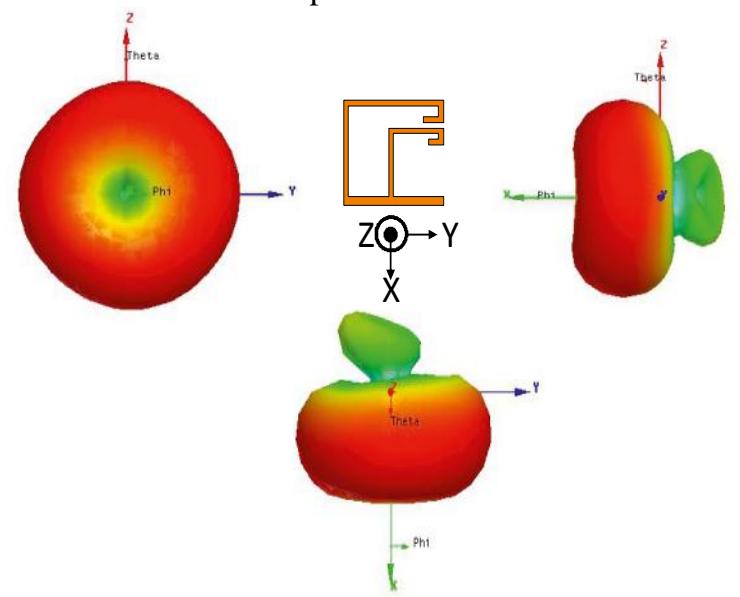

Figure 5b: 3-D simulation radiation patterns in Y-Z, X$\mathrm{Z}$, and $\mathrm{X}-\mathrm{Y}$ plane at $5.2 \mathrm{GHz}$

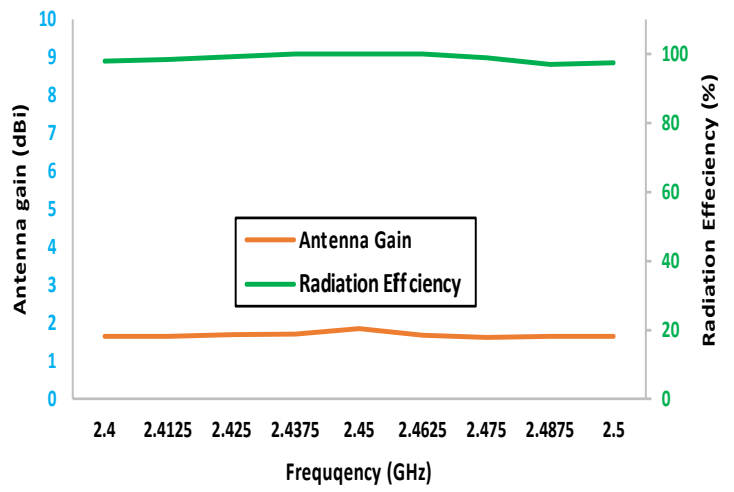

Figure 6a: Antenna simulated gain and radiation efficiency at $2.45 \mathrm{GHz}$ band

To show the clarity of this research the antenna structure and its performances in this paper is compared to two of the previously conducted works regarding dongle antenna design and analysis. As it can be seen from table 2, the proposed antenna over all profile is smaller to the antennas presented in the other two papers. In addition, the proposed antenna performance in terms of bandwidth, gain and radiation efficiency is same or better than other proposed units.

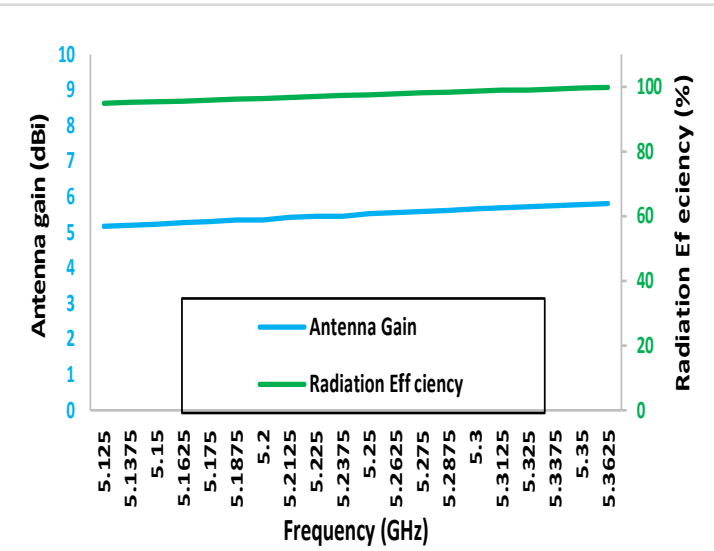

Figure 6b: Antenna simulated gain and radiation efficiency at $5.2 \mathrm{GHz}$ band

Table 2: Comparison of the proposed antenna with previous works

\begin{tabular}{|c|c|c|c|}
\hline & This paper & $\begin{array}{l}\text { Reference } \\
\text { (1) }\end{array}$ & Reference(2) \\
\hline Overall size & $\begin{array}{c}40 \times 10 \times 0.8 \\
\mathrm{~mm}^{3}\end{array}$ & $\begin{array}{c}60 \times 17 \times 0.8 \\
\mathrm{~mm}^{3}\end{array}$ & $\begin{array}{c}45 \times 10 \times 0.8 \\
\mathrm{~mm}^{3}\end{array}$ \\
\hline $\begin{array}{l}\text { Structure } \\
\text { complexity }\end{array}$ & $\begin{array}{l}\text { planar and } \\
\text { modest }\end{array}$ & $\begin{array}{l}\text { planar and } \\
\text { modest }\end{array}$ & $\begin{array}{l}\text { planar and } \\
\text { complex }\end{array}$ \\
\hline $\begin{array}{l}10 \mathrm{~dB} \\
\text { return loss } \\
\text { bandwidth }\end{array}$ & $\begin{array}{c}\text { acceptable at } \\
\text { both } 2.45 \text { and } \\
5.25 \mathrm{GHZ} \\
\text { bands }\end{array}$ & $\begin{array}{l}\text { acceptable at } \\
5.2 \mathrm{GHz} \text { band } \\
\text { and narrow at } \\
2.4 \mathrm{GHz} \text { band }\end{array}$ & $\begin{array}{c}\text { acceptable at } \\
\text { both } 2.45 \text { and } \\
5.25 \mathrm{GHZ} \\
\text { bands }\end{array}$ \\
\hline $\begin{array}{l}\text { Antenna } \\
\text { gain }(\mathbf{d B i})\end{array}$ & $\begin{array}{c}1.4 \text { average at } \\
2.4 \mathrm{GHz} \\
5.3 \text { average at } \\
5.2 \mathrm{GHz}\end{array}$ & N.A. & $\begin{array}{c}-0.5 \text { at } 2.4 \mathrm{GHz} \\
2.5 \text { at } 5.2 \mathrm{GHz}\end{array}$ \\
\hline $\begin{array}{c}\text { Total } \\
\text { radiation } \\
\text { efficiency }\end{array}$ & $\begin{array}{l}>90 \% 2.4 \mathrm{GHz} \\
>94 \% 5.2 \mathrm{GHz}\end{array}$ & N.A. & N.A. \\
\hline $\begin{array}{c}\text { Application } \\
\text { s }\end{array}$ & $\begin{array}{c}\text { WLAN } \\
(2.45,5.25) \mathrm{GH} \\
\mathrm{z} \text { bands }\end{array}$ & $\begin{array}{c}\text { WLAN } \\
2.4 \mathrm{GHz} \text { and } \\
5.7 \mathrm{GHz} \\
\text { bands }\end{array}$ & $\begin{array}{c}\text { WLAN } \\
(2.45,5.5) \text { and } \\
3.5 \mathrm{GHz} \text { bands }\end{array}$ \\
\hline
\end{tabular}

\section{Conclusions}

A compact low profile and simple F-Shaped USB dongle is proposed in this paper. The simulated and the measured return loss results were best matched. The antenna is a good choice for small portable Wireless Local Area Networks (IEEE $802.11 \mathrm{a} / \mathrm{b} / \mathrm{g}(2.4-2.484 \mathrm{GHz}$ and $5.15-$ $5.35 \mathrm{GHz}$ ) for its satisfactory impedance bandwidth at $10 \mathrm{~dB}$ return loss. Smooth Omni-directional radiation pattern with good performance in gain and radiation efficiency is the key futures of the proposed antenna. 


\section{References}

[1] Wen S. C., Bau Y. Lee, Jing J. L., Ke M. L. , Ching Y. H. nd Chin k. Y.(2013). A PIFA type USB Dongle antenna for WLAN applications. Cross Strait Quad-Regional Radio Science and Wireless Technology Conference (IEEE). pp. 203 206.

[2] Bruno R. F., Hans A., Mauricio H. C. D. and Tan P. V. (2014). A compact IFA-based dual-band planar antenna for WiFi USB dongles. The 8th European Conference on Antennas and Propagation (IEEE). pp. 325-329.

[3] Wen S. C., Chia Y. H. and Wen. H. H. (2016). Coupled-fed printed multi-arm monopole antenna for USB dongle application. IEEE International Workshop on Electromagnetics: Applications and Student Innovation Competition. pp. 1-2.

[4] Wen. J. L., Shih. H. C., Jiun. T. Y. and Bo R. H. (2014). Compact Dual-Band WLAN Diversity Antennas on USB Dongle Platform. IEEE Transactions on Antennas and Propagation. vol. 62, no. 1, pp. 109-118.

[5] Luo Q., Pereira J. R., Salgado H. M.(2009) "Fractal Monopole Antenna for WLAN USB Dongle," Loughborough Antennas \& Propagation Conference(IEEE), pp. 245-247.

[6] Chaimool S., Chokchai C. and Akkaraekthalin P.(2012). Multiband loaded fractal loop monopole antenna for USB dongle applications. Electronics Letters, vol. 48, pp. 1446-1447. 